\title{
Reviewing the trend of health artificial intelligence technology in COVID-19 pandemic prevention
}

\author{
Weide Tsai ${ }^{1,2,3}$, Wen-Han Chang ${ }^{1,2,3,4,5,6}$ \\ ${ }^{1}$ Department of Medicine, Mackay Medical College, New Taipei, Taiwan; ${ }^{2}$ Department of Emergency Medicine, Mackay Memorial Hospital, Taipei, \\ Taiwan; ${ }^{3}$ Mackay Medicine, Nursing and Management College, Taipei, Taiwan; ${ }^{4}$ Institute of Mechatronic Engineering, National Taipei University \\ of Technology, Taipei, Taiwan; ${ }^{5}$ Graduate Institute of Injury Prevention and Control, College of Public Health and Nutrition, Taipei Medical \\ University, Taipei, Taiwan; ${ }^{6}$ Department of Emergency, School of Medicine, College of Medicine, Taipei Medical University, Taipei, Taiwan \\ Contributions: (I) Conception and design: WH Chang; (II) Administrative support: All authors; (III) Provision of study materials or patients: All \\ authors; (IV) Collection and assembly of data: All authors; (V) Data analysis and interpretation: All authors; (VI) Manuscript writing: All authors; (VII) \\ Final approval of manuscript: All authors. \\ Correspondence to: Wen-Han Chang. 92, Section 2, Chung-shan North Road, Taipei, Taiwan. Email: branden888@gmail.com.
}

\begin{abstract}
The novel coronavirus pneumonia originated in Wuhan, China, in December 2019, and it then spread rapidly into many countries around the world in the beginning of 2020. By June 2020, more than 7 million people had been infected and more than 400,000 people died, thus making it a global disaster. With the development of science and technology, the Internet has evolved to a $5 \mathrm{G}$ bandwidth, and the application of i-cloud computing technology has also matured. Moreover, big data and artificial intelligence (AI) have also become mainstream approaches for epidemic prevention, and they have been integrated into the practical application of various medical services and quarantine measures in epidemic prevention efforts. Many research and development teams have invested vast resources to improve technology and its application, resulting in numerous suitable AI products for epidemic prevention. Epidemic prevention is quite challenging because it is necessary to avoid contact with other people to prevent virus transmission, reduce environmental pollution and air transmission, and strictly control the medical service process, all of which will affect the quality of medical treatment to varying degrees. The continued integration of health artificial intelligence (HAI) and medical-related technologies will greatly aid in future efforts to end the COVID-19 pandemic.
\end{abstract}

Keywords: Artificial intelligence (AI); coronavirus epidemic; robot; medical service; COVID-19

Received: 06 August 2020; Accepted: 07 December 2020; Published: 30 April 2021.

doi: $10.21037 /$ ht-20-27

View this article at: http://dx.doi.org/10.21037/ht-20-27

The current COVID-19 pandemic has triggered the opportunity for health artificial intelligence (HAI) technology to be applied to medical treatments or aspects of public society (1). The application of HIT to medical treatment is partially restricted. Some studies show that the skill of and trust in technology are not sufficient to meet the requirements of various medical or health needs $(2,3)$. For HAI technology to be used in medical applications, it must be precise, convenient, immediate, and cheap and able to provide medical personnel with a more humanized use, so that can help them do their jobs better, giving them the tools to build a smarter, more efficient ecosystem (4-6). It should be noted that the current AI smart devices are, in most cases, too expensive, and importantly, there are few devices that have become essential for medical processes (7-9). This has slowed or paused the research and development of some HAI technologies. Notably, in this epidemic, COVID-19 can be transmitted through interpersonal contact, with possibly fatal results. A large amount of pressure from this pandemic will necessitate the development of more HAI technologies $(10,11)$. HAI innovations are needed to solve the issues related to the 
requirement of close contact in medical clinics for diagnosis and treatment, and this highlights the importance of HAI in the clinic, including some originally expensive robots or remote monitoring equipment. Through the use of HAI, it can be possible to obtain a medical diagnosis without coming to a hospital or clinic (12-15).

\section{Objective}

We review the relevant literature on the use of HAI in epidemic prevention and cover the concepts and products that have been developed and applied to the prevention of the novel coronavirus epidemic. The method used for this review involved collecting reports or information published by the media or on networks regarding efforts to prevent COVID-19 or issues related to medical services. The goal of this literature review is that the future HAIEP products will better meet the needs of medical services and epidemic control, and innovative examples will be provided to encourage intelligent experts to invest in the field of HAI epidemic prevention.

\section{Impact and influence of COVID-19}

The novel coronavirus epidemic has had a huge impact on many countries and medical systems $(16,17)$. The high infectivity of the novel coronavirus challenges the epidemic prevention ability of medical systems worldwide. It has also required changes to the process of hospital medical treatment and the behavior of medical staff, resulting in a new medical service model (18). The novel coronavirus can remain in the air for a long time, it spreads via respiratory droplets, which are tiny drops of liquid that enter the air when a person coughs, sneezes, or talks. The results, published in PNAS found that loudly talking can emit thousands of these droplets into the air, remaining airborne for around 8-14 minutes in a confined space (19). Also, it is easily spread through contact, which makes preventing its spread in hospitals difficult; epidemic prevention efforts have also exposed many defects in traditional medical processes (20). To prevent the spread of the novel coronavirus, experts have attempted to meet the requirements of the epidemic prevention by applying HAI immediately (21-23). For patient visits, hospitals have made large investments to purchase HAI epidemic prevention equipment for isolation, detection and screening, infection control, care, and medical treatment, which has greatly changed the future medical service mode (24). The novel coronavirus epidemic has indeed brought great changes to the relationship between medical staff and patients. Through these changes, we can make the entire medical treatment process safer and make the overall medical demand move toward the direction of HAI epidemic prevention (25).

\section{Application of hospital intelligence in the control of the COVID-19 epidemic}

With the spread of COVID-19, the virus has also become prevalent in different seasons. The epidemic situation has become the normal situation that hospitals will often face in the future, markedly changing the way medical services are provided and making potential intelligent technology that can be used to assist medical personnel in epidemic prevention a useful tool (26). Inappropriate epidemic prevention equipment will interfere with the provision of medical services, causing difficulties in epidemic prevention (27). Currently, many new intelligent technologies are used for medical epidemic prevention, and these are quite successful and relied on (28). It is very important for the future development of advanced intelligent medical treatment to review studies on how to use intelligent technology for epidemic prevention that were published during the novel coronavirus epidemic to understand the effectiveness of COVID-19 epidemic control (29-31). The application of AI in epidemic prevention plays an important role and will change the ecology of the traditional medical industry (32). Reviewing the application of the reported AI methods used in the epidemic prevention process and understanding the potential of big data analysis will help to develop proper HAI methods for epidemic prevention by medical services, including electronic medical records, medical image recognition, health equipment, and diagnosis and treatment systems. Finally, using the existing big data, the risk of the novel coronavirus epidemic is analyzed to provide valuable information for doctors to enable them to best prepare for epidemic prevention $(33,34)$.

\section{Health artificial Intelligent screening for COVID-19}

A Chinese company has released an advanced surveillance system (SenseTime) that uses facial recognition technology and temperature detection software to identify people who may have a fever and are more likely to be infected with the 
virus (35). According to the patient's monitoring report, the combination of respiratory frequency, heart rate, and body temperature (BT) may determine whether he/she is infected with COVID-19. This intelligent system combines and calculates the changes in the patient's symptoms and the data obtained by the sensor and uses a machine to perform big data analysis to automatically detect possibly infected individuals during the medical service process and reduce the burden on the medical system caused by epidemic prevention. The device can automatically generate a series of data through a specially designed application program in response to report parameters, and through a calculation analysis, it can identify those who may be infected with the novel coronavirus. The best solution for epidemic prevention to prevent the recurrence of the novel coronavirus seems to be have every person wear a detection device $(36,37)$.

Google Company has developed a "Wuhan pneumonia history track comparison" website. It requires enabling the positioning system of the Google Maps application. By comparing the historical location records from their mobile phone, users can determine whether they have been in contact with patients. Users need to first ensure that the location record function of their mobile phone is turned on, select the download time interval, and then download their own history tracking data. They can then load the file to compare the time and place of a footprint and finally obtain the comparison results to confirm whether they need to self-isolate (38).

\section{Reorganization of COVID-19 epidemic information and intelligent notification and control}

Taiwan's epidemic situation command center uses technological measures to assist in epidemic prevention operations. These include the "entry quarantine system" for the entry of people into the country to accelerate the inspection process and procedures using electronic entry data and the "electronic fence intelligent monitoring system" for tracking locations through mobile phone positioning; these measures effectively aid in the implementation of anti-epidemic measures. When a passenger enters the country from a foreign country, an entry quarantine data file will be built. In addition to filling in health declarations and other information online, a 14day home care "epidemic prevention tracking system" and a tracking "electronic fence system" are also integrated. Using the mobile phone location of the individual in home quarantine, if the home-quarantined individual leaves the limited area, the system will automatically send a warning message to the party, civil affairs unit, health administration unit, and the police in the jurisdiction. After receiving the notice, police officers will quickly check the movements of the individual to determine whether he/she left the quarantine area $(39,40)$. With this system, all of the movements of the individual since arriving in Taiwan can be acquired. Notably, some companies have developed AI talking robots (voice assistants) to share the latest epidemic information. AI robots provide travelers with up-to-date travel information, local epidemic prevention regulations, and the risks posed by COVID-19 (41).

In order to prevent COVID-19 pneumonia, the Taiwan Executive Yuan used AI big data to invest in epidemic prevention, broadcasting messages to passengers at regular intervals in response to the flow of people in scenic spots so that tourists could be aware of the number of people at a scenic spot to prevent overcrowding and reduce opportunities for COVID-19 cross-infection (42).

\section{Design of intelligent telemedicine services for patients with COVID-19}

Because telemedicine principally focuses on transmitting medical information, VR has the potential to enhance this function. Particularly, VR can be used in telemedicine as an advanced communication interface, which enables a more intuitive mode of interacting with information, and as a flexible environment that enhances the feeling of physical presence during the interaction (43). The virtual medicine model can help return people's lives to normal by eliminating worries about where to see a doctor while also solving problems associated with the shortage of medical care and high medical costs during the epidemic (44-46). In addition, the American telemedicine companies Amwell and Teladoc are promoting special appointments for patients with coronavirus infections $(47,48)$. XRHealth provides VR headmounted devices that allow doctors to remotely monitor patients with COVID-19 and use VR to walk into the patient's room for a virtual consultation and diagnosis (49).

Meanwhile, the use of AI in telemedicine can assist doctors in providing better services to patients by simplifying their work practices. The addition of AI in screening procedures may help to create a suitable VR environment for the needs of patients, who can discuss problems with the medical team and seek solutions in a realistic and safe virtual space through the VR platform. 
Such as doctors at the Washington State Medical Center used the Vici long-range device developed by InTouch Health to treat the first patient diagnosed with the novel coronavirus in the United States; it allows doctors to interact with patients through a screen without actual contact. Doctors can use this device to talk to patients and perform basic diagnostic functions, such as taking a temperature and using a stethoscope (50). In addition, the hospital began to use the remote equipment system for medical notes, discussions, and teaching, allowing medical colleagues to share their experiences and discuss their cases online to overcome restrictions caused by the epidemic and prevent delays in disease treatment. The AI remote design also provides the opportunity for medical students to learn online, and it also increases the demand for remote testing (51-53).

\section{Use of intelligent design to ensure the safety of family members in quarantine because of COVID-19}

The intelligent design to ensure the safety of family members in quarantine due to COVID-19 related had been used in many countries $(54,55)$. AR/VR provides those isolated at home with entertainment and sports options, such as AR/VR games through the TV or computer and entertainment and sports programs, which can help reduce psychological fears while in isolation. HTC operates automatically through the LINE Bot system platform, enabling those in home quarantine to actively report their health status through the LINE Bot system. It can be used to obtain information about epidemic prevention assistance and take some of the workload from first-line care personnel (56).

We can protect our family and ourselves by making good use of smart devices at home by voice controlling and reducing contact with our belongings (57). Kevin C. Tofel, an American technology expert, was infected with the new coronavirus and was isolated at home for 8 days (58). In an article published in "Stacey on IOT", he pointed out that the design of smart home appliances and devices installed in his home helped him reduce contact with his family, and he could avoid touching anything that would infect his family (59). There are increasingly more Internet of things devices available for the home. Through either voice control or an APP, such devices can reduce the chance of exposure to the virus that causes COVID-19. This will be an important way in the future to reduce exposure to the virus that causes COVID-19 using existing home HAI devices that are used without direct contact, allowing individuals quarantined at home because they are infected with the novel coronavirus to use HAI devices to access the Internet without infecting the other people $(60,61)$.

The "smart cabinet" is also a good way to solve problems with delivering items to those in quarantine (62). The system sends a message containing a password to the recipient in quarantine. After receiving the message, the recipient can ask a family member to pick up the goods and store them outside the quarantine area or collect them after the quarantine is over. The smart cabinet can receive and send services 24 hours a day, with convenience, security, and privacy (63). During epidemic prevention periods, the social distance between people should be $1 \mathrm{~m}$ outdoors and $1.5 \mathrm{~m}$ indoors (64). Wearing masks and washing hands frequently are not sufficient, and it is also necessary to avoid touching objects that could be contaminated, thus reducing the chances of contact and infection. The "touch free" function of intelligent equipment is very helpful in the epidemic prevention period to protect the user. Taking advantage of the convenience brought by the Internet of things to the novel coronavirus prevention efforts, good outcomes have been reported $(65,66)$.

\section{Intelligent triage design for COVID-19}

MEGV II has developed an infrared instrument that can measure the BT of everyone in a crowd within 5 meters. It can measure about 300 people per second, with an error of less than $0.3{ }^{\circ} \mathrm{C}$. It helps emergency personnel to identify individuals with a fever and avoid coming too close to them (67).

The company Baidu also uses infrared cameras to measure the face temperature of each batch of 3-5 people, quickly warning those who are over the normal BT and then further using the frontal temperature detector to measure their BT more carefully to quickly divert the flow of patients for primary screening by BT $(68,69)$. The company China Mobile also uses $5 \mathrm{G}$ transmission to quickly measure the BT of many people simultaneously using infrared photography technology $(70,71)$.

Kronikare, a Singapore company, has released the "iThermo" temperature sensor. Through a combination of smart phones, thermal and laser sensing cameras, and APPs, the faces of 10 people at a time can be extracted from a range of 1 to 3 meters for analysis, and $8-10$ people can be measured every minute. The Kronikare sensor is suitable for temperature detection on a small scale in offices, 
shopping malls, and other areas (72).

\section{Application of intelligent disinfection equipment for COVID-19 epidemic prevention}

Intelligent epidemic prevention measures will affect the quality of medical treatment (73). The proper fit of masks and protective clothing on medical staff can be detected by an intelligent face recognizer, and then, medical staff can be reminded to be careful to reduce the chance of infection. The intelligent design of hospital medical treatments helps doctors to monitor interactions within crowds at any time. Patients experiencing physical discomfort should be evaluated first using a remote medical consultation before they come to the hospital to avoid the chance of crossinfection. This can reserve the hospital for patients with serious conditions.

\section{Intelligent distribution and control of COVID-19 epidemic prevention materials}

Some companies have noted that $3 \mathrm{D}$ printing can help supply medical and epidemic prevention materials. Products printed by intelligent 3D machines are usually soft and flexible, with diverse shapes. SmileDirect Club (SDC), one of the largest 3D printing manufacturers in the United States, has opened production facilities and donated materials for the $3 \mathrm{D}$ printing of masks to expand the production of masks, respirator valves, and other medical product supplies (74). In addition, some companies use an App to manage their medical supplies. Using a mask App, it can be possible to determine where masks are sold and control the number of masks purchased through intelligent management to lower the price of masks (75).

\section{Big data analysis to monitor the risk of the COVID-19 epidemic}

As early as October 2019, using the big data to detect carbon emissions, we can see that many hospitals in Wuhan, China, had more traffic flow than during the same period last year, and the number of hospital visits increased $(76,77)$. In addition, based on Google's query data, searches for related words, especially queries including upper respiratory symptoms or unknown causes of infection, are also increasing, indicating the occurrence of an unknown epidemic situation $(78,79)$. In addition, using satellite data to understand the distribution and quantity of sulfur dioxide, it is possible estimate the how much incineration is occurring in a community, which reflects whether many bodies are being incinerated, thus allowing estimation of the severity of the epidemic $(80,81)$.

BLUEDOT, a Canadian company, tracks the risk of COVID-19 through AI and predicts the possibility of a serious outbreak using big data analysis (82). The United States has also created a COVID-19 prediction model combining a monitoring APP, wearable device, and AI that can detect $90 \%$ of asymptomatic patients in advance. The Rockefeller Institute of Neuroscience (RNI) and Oura jointly developed an $\mathrm{AI}$ health model and released the test results for more than 600 medical staff, which showed that the model could give an early warning 3 days before the subjects had symptoms of COVID-19, with an accuracy of $90 \%$. Smart wearable devices and HAI technology have been widely used in this new coronavirus epidemic prevention campaign (83). Fitbit, a smart watch, also announced in April that it would cooperate with Stanford Medical College to develop algorithms to detect the early symptoms of viral infection, such as those of the virus that causes COVID-19 (84). In March, UCSF also cooperated with Oura Health to develop algorithms to identify COVID-19 infections early (85).

\section{Intelligent diagnosis of COVID-19 using AI images}

The company AI has launched a coronavirus HAI solution that can help first-line medical workers effectively detect and monitor the disease (86). The solution improves the CT diagnosis speed for COVID-19 pneumonia. In addition, Alibaba has built an AI-driven diagnosis system and claims that it can accurately diagnose the virus in a few seconds (87). A company in Taiwan cooperated with Taipei Medical University to develop a method for the diagnosis of novel coronavirus pneumonia using a chest $\mathrm{X}$-ray, also achieving good results. Based on their research results, over $90 \%$ of patients can first be evaluated regarding COVID-19 status using a chest $\mathrm{X}$-ray, allowing doctors to be warned about increasing their own protection measures (88-90).

\section{Al intelligent block chain system that provides online platform to consult with doctors and apply for medical insurance}

To reduce the contact between doctors and patients, 
we started a mode of remote online medical treatment using online consultations to diagnose possible novel coronavirus infections and arrange for necessary medical measures and reduce the spread of the infection through contact (91-93). ANT financial provides a block chain platform to help expedite insurance claims and reduce the need for face-to-face contact between patients and medical staff $(94,95)$.

\section{Intelligent hospital processes and other services}

It is feasible to use drones to deliver medical supplies. During the period of disease transmission, the delivery of medical supplies presents many problems, including avoiding contact opportunities and being able to deliver supplies to where they are needed to ensure the safest infection control conditions $(96,97)$. The Terra Drone Company uses its drones to transport medical and quarantine materials and supervises those in isolation to ensure the best epidemic prevention effect (98). Many local governments in China also use drones for material transport and delivery of consumer goods from the air and to spray disinfectant, warn people about gatherings, monitor whether people are wearing masks, and measure people's temperature using infrared rays to determine if someone has a fever $(99,100)$.

AI robots also play an important role in epidemic prevention (101,102). The company Shenyang Xinsong develops intelligent delivery robots, Qingdao Wuniu studies intelligent technology disinfection robots, Jingdong Logistics works on intelligent distribution robots, and Guangzhou Gaoxin group uses $5 \mathrm{G}$ for police patrol robots (103-106). Many other companies can quickly measure BT by infrared and identify people within 5 meters and detect whether someone is wearing a mask $(107,108)$. Blue Ocean Robotics's UVD robot can carry out risk tasks such as disinfection, delivery of food and supplies, and the automatically use ultraviolet rays to kill bacteria and viruses (109). In China, the Purdue Technology Company has supplied robots to more than 40 hospitals in China for catering purposes (110).

\section{Use of Al technology to develop treatments and expedite drug development}

Google's Deepmind Division has used its most accurate AI algorithm and computing power to better understand the proteins of the virus that causes COVID-19, and it has published its findings to help other companies develop therapeutic drugs (111). Benevolentai uses AI systems to make drugs that can fight the world's most serious diseases, and it is now supporting the work of treating coronaviruses (112). Vaccines are being developed with the use of supercomputers. Researchers are using cloud computing resources and supercomputers from major technology companies such as Tencent, Didi, and Huawei to quickly track COVID-19 treatment methods and vaccine development efforts (113).

\section{Conclusions}

The use of HAI technology in medicine still faces many challenges, and the integrated efforts to stop the COVID-19 epidemic have shown some promising success. At this stage, the novel coronavirus pneumonia continues to spread, and intelligent technologies such as image analysis, HAI language, deep learning, data networks, wearable intelligence, and the Internet of things have been rapidly developed to help stop the spread of novel coronavirus infections. Based on the reviewed studies, it is clear that regardless of the medical experiment, medical diagnosis, or epidemic, to make HAI technology work, it will be necessary to combine more biological information, clinical medical knowledge, and other data. There are currently many breakthroughs being reported regarding the use of HAI technology for COVID-19 or other medical vaccine research, intelligent medical diagnosis, and other applications. The continued integration of HAI and medical-related technologies will lead to the elimination of COVID-19 in the future (114).

\section{Acknowledgments}

Funding: None.

\section{Footnote}

Conflicts of Interest: Both authors have completed the ICMJE uniform disclosure form (available at http://dx.doi. org/10.21037/ht-20-27). WHC serves as an Editor-in-Chief of Health Technology. The other author has no conflicts of interest to declare.

Etbical Statement: The authors are accountable for all aspects of the work in ensuring that questions related to the accuracy or integrity of any part of the work are appropriately investigated and resolved. 
Open Access Statement: This is an Open Access article distributed in accordance with the Creative Commons Attribution-NonCommercial-NoDerivs 4.0 International License (CC BY-NC-ND 4.0), which permits the noncommercial replication and distribution of the article with the strict proviso that no changes or edits are made and the original work is properly cited (including links to both the formal publication through the relevant DOI and the license). See: https://creativecommons.org/licenses/by-nc-nd/4.0/.

\section{References}

1. Using artificial intelligence to help combat COVID-19. OECD. Accessed April 23, 2020. Available online: https:// www.oecd.org/coronavirus/policy-responses/usingartificial-intelligence-to-help-combat-covid-19-ae4c5c21/

2. Hatherley JJ. Limits of trust in medical AI. J Med Ethics 2020;46:478-81.

3. Ryan M. In AI We Trust: Ethics, Artificial Intelligence, and Reliability. Sci Eng Ethics 2020;26:2749-67.

4. Guo J, Li B. The Application of Medical Artificial Intelligence Technology in Rural Areas of Developing Countries. Health Equity 2018;2:174-81.

5. Bushko RG. Situated, strategic, and AI-Enhanced technology introduction to healthcare. Stud Health Technol Inform 2005;118:273-7.

6. Shen J, Zhang CJP, Jiang B, et al. Artificial Intelligence Versus Clinicians in Disease Diagnosis: Systematic Review. JMIR Med Inform 2019;7:e10010.

7. Howard J. Artificial intelligence: Implications for the future of work. Am J Ind Med 2019;62:917-26.

8. Han J, Kang HJ, Kwon GH. An Ecological Approach to an Intelligent Healthscape for a Medical Service Robot. Jpn J Ergon 2019;55:1H3-7.

9. Kang HJ, Han J, Kwon GH. An Ecological Approach to Smart Homes for Health Care Services: Conceptual Framework of a Smart Servicescape Wheel. JMIR Mhealth Uhealth 2019;7:e12425.

10. Tahir A, Qiblawey Y, Khandakar A, et al. Coronavirus: Comparing COVID-19, SARS and MERS in the eyes of AI. arXiv: 2005.11524. Available online: https://arxiv.org/ abs/2005.11524.

11. Sipior JC. Considerations for development and use of AI in response to COVID-19. Int J Inf Manage 2020;55:102170.

12. Cerf VG. Implications of the COVID-19 pandemic. Commun ACM 2020;63:7.

13. Xu Y, Ma L, Yang F, et al. A collaborative online AI engine for CT-based COVID-19 diagnosis. Preprint. medRxiv
2020;2020.05.10.20096073.

14. Council J. NIH, Nvidia Use Covid-19 Patient Data to Build Diagnostic System. WSJ PRO Artificial Intelligence. Accessed May 14, 2020. Available online: https://www. wsj.com/articles/nih-nvidia-use-covid-19-patient-data-tobuild-diagnostic-system-11589448600

15. Engler A. A guide to healthy skepticism of artificial intelligence and coronavirus. The Brookings Institution. Accessed April 2, 2020. Available online: https://www. brookings.edu/research/a-guide-to-healthy-skepticism-ofartificial-intelligence-and-coronavirus/

16. Assessment Report on Impact of COVID-19 Pandemic on Chinese Enterprises. UN Development Programme. Accessed April 7, 2020. Available online: https://www. cn.undp.org/content/china/en/home/library/crisis_ prevention_and_recovery/assessment-report-on-impactof-covid-19-pandemic-on-chinese-ente.html

17. Viet Nam. Rapid Assessment of the Socio-economic impact of COVID-19 on persons with disabilities in Viet Nam. UN Development Programme. Accessed May 11, 2020. Available online: https://www.vn.undp.org/content/ vietnam/en/home/library/democratic_governance/ ImpactPwDs.html

18. Zheng N, Du S, Wang J, et al. Predicting COVID-19 in China Using Hybrid AI Model. IEEE Trans Cybern 2020;50:2891-904.

19. Stadnytskyi V, Bax CE, Bax A, et al. The airborne lifetime of small speech droplets and their potential importance in SARS-CoV-2 transmission. Proc Natl Acad Sci U S A 2020;117:11875-7.

20. Khanna RC, Cicinelli MV, Gilbert SS, et al. COVID-19 pandemic: Lessons learned and future directions. Indian J Ophthalmol 2020;68:703-10.

21. Block J. COVID-19 puts spotlight on artificial intelligence. Gen Edge. Accessed May 11, 2020. Available online: https://www.genengnews.com/gen-edge/covid-19-putsspotlight-on-artificial-intelligence/

22. Mei X, Lee HC, Diao K, et al. Artificial intelligenceenabled rapid diagnosis of COVID-19 patients. Preprint. medRxiv 2020;2020.04.12.20062661.

23. Kessler A. How big data is attacking the coronavirus. Accessed May 3, 2020. Available online: https://www. wsj.com/articles/how-big-data-is-attacking-thecoronavirus-11588541839

24. Heaven WD. Our weird behavior during the pandemic is messing with AI models. MIT Technology Review. Accessed May 11, 2020. Available online: https://www. technologyreview.com/2020/05/11/1001563/covid- 
pandemic-broken-ai-machine-learning-amazon-retailfraud-humans-in-the-loop/

25. Hakkennes S. Healthcare Technology Innovations for Identifying and Managing COVID-19 Patients. Gartner. Accessed April 06, 2020. Available online: https:// www.gartner.com/en/documents/3983039/healthcaretechnology-innovations-for-identifying-and-ma

26. Wright K. An AI Assist for Spotting COVID-19 in X Rays. APS physics. Accessed May 5, 2020. Available online: https://physics.aps.org/articles/v13/73

27. Khan S, Siddique R, Li Z, et al. COVID-19 pandemic; prevention, treatment, and mental health. Hum Vaccin Immunother 2020;16:2215-6.

28. Marr B. Coronavirus: How Artificial Intelligence, Data Science And Technology Is Used To Fight The Pandemic. Forbes. Accessed March 13, 2020. Available online: https://www.forbes.com/sites/bernardmarr/2020/03/13/ coronavirus-how-artificial-intelligence-data-science-andtechnology-is-used-to-fight-the-pandemic/\#14ad046b5f5f

29. Hossain MM, Sarwar SA, McKyer ELJ, et al. Applications of Artificial Intelligence Technologies in COVID-19 Research: A Bibliometric Study. Preprints 2020, 2020060161. Available online: https://www.preprints.org/ manuscript/202006.0161/v1

30. Lai Y, Yeung W, Celi LA. Urban Intelligence for Pandemic Response: Viewpoint. JMIR Public Health Surveill 2020;6:e18873.

31. Cho A. AI systems aim to sniff out coronavirus outbreaks. Science 2020;368:810-1.

32. Alimadadi A, Aryal S, Manandhar I, et al. Artificial intelligence and machine learning to fight COVID-19. Physiol Genomics 2020;52:200-2.

33. Albahri AS, Hamid RA, Alwan JK, et al. Role of biological Data Mining and Machine Learning Techniques in Detecting and Diagnosing the Novel Coronavirus (COVID-19): A Systematic Review. J Med Syst 2020;44:122.

34. Bragazzi NL, Dai H, Damiani G, et al. How Big Data and Artificial Intelligence Can Help Better Manage the COVID-19 Pandemic. Int J Environ Res Public Health 2020;17:3176.

35. Li J. China's facial-recognition giant says it can crack masked faces during the coronavirus. QUARTZ. Accessed February 18, 2020. Available online: https:// qz.com/1803737/chinas-facial-recognition-tech-cancrack-masked-faces-amid-coronavirus/

36. Thomas A. AI Facial Recognition Vs Contact Biometric Systems Amid Covid-19. Analytics India Magazine.
Accessed May 16, 2020. Available online: https:// analyticsindiamag.com/ai-facial-recognition-vs-contactbiometric-systems-amid-covid-19/

37. ADMIN. AI Solutions creates breakthrough in war against Covid-19. Marketing MAGAZINE. Accessed March, 2020. Available online: https://marketingmagazine.com. my/ai-solutions-creates-new-breakthrough-in-waragainst-covid-19/

38. Holmes A. Governments have to decide whether to scrap their own COVID-19 contact tracing apps in favor of tech built by Apple and Google. Here's what's at stake. Business Insider. Accessed April 27, 2020. Available online: https://www.businessinsider.nl/coronavirus-contacttracing-government-apps-vs-apple-google-covid-19-20204? international $=$ true $\& r=U S$

39. Wang CJ, Ng CY, Brook RH. Response to COVID-19 in Taiwan: Big Data Analytics, New Technology, and Proactive Testing. JAMA 2020;323:1341-2.

40. Chen YY, Lim E. CORONAVIRUS/MOFA launches web page to showcase Taiwan model in COVID-19 fight. Focus Taiwan- CNA English News. Accessed April 29, 2020. Available online: https://focustaiwan.tw/ politics/202004290016

41. Yasuhiro Y. Advancing Customer Communications via AIRobot Linkages. NEC Tech J 2017;11 21-25. Available online: https://www.nec.com/en/global/techrep/journal/ g16/n02/160206.html

42. Lin S. VIDEO: COVID-19: Popular Taichung spot caps visitor numbers. Radio Taiwan International. Accessed April 17, 2020. Available online: https://en.rti.org.tw/ news/view/id/2003103

43. Riva G, Gamberini L. Virtual reality in telemedicine. Telemed J E Health 2000;6:327-40.

44. Mahajan V, Singh T, Azad C. Using Telemedicine During the COVID-19 Pandemic. Indian Pediatr 2020;57:652-7.

45. Contreras CM, Metzger GA, Beane JD, et al.

Telemedicine: Patient-Provider Clinical Engagement During the COVID-19 Pandemic and Beyond. J

Gastrointest Surg 2020;24:1692-7.

46. Ohannessian R, Duong TA, Odone A. Global Telemedicine Implementation and Integration Within Health Systems to Fight the COVID-19 Pandemic: A Call to Action. JMIR Public Health Surveill 2020;6:e18810.

47. Lovett L. Amwell scores \$194M, as telehealth business booms during coronavirus pandemic. Mobi health news. Accessed May 20, 2020. Available online: https:// www.mobihealthnews.com/news/amwell-scores-194mtelehealth-business-booms-during-coronavirus-pandemic 
48. Pifer R. Coronavirus drives surge in Teladoc virtual medical visits. Healthcare Dive. Accessed April 15, 2020. Available online: https://www.healthcaredive.com/news/ coronavirus-COVID-surge-teladoc-telehealth-virtualmedical-visits/576031/

49. Matney L. VR telemedicine platform XRHealth raises \$7M. Techcrunch. Accessed April 22, 2020. Available online: https://techcrunch.com/2020/04/22/vrtelemedicine-platform-xrhealth-raises- $7 \mathrm{~m} /$

50. InTouch Technologies, Inc. InTouch ViciTM User Guide. InTouch health. Accessed November, 2018. Available online: https://cloud.kapostcontent.net/pub/2af3f4ce83e6-48b3-b80d-150188aa7131/enterprise-collateral-viciuser-guide.pdf?kui=Gnkia42OKUpA3W3W1-nZ9g

51. Daniel SJ. Education and the COVID-19 pandemic. Prospects 2020;49:1-6.

52. Ashokka B, Ong SY, Tay KH, et al. Coordinated responses of academic medical centres to pandemics: Sustaining medical education during COVID-19. Med Teach 2020;42:762-71.

53. Seymour-Walsh AE, Weber A, Bell A. Practical approaches to pedagogically rich online tutorials in health professions education. Rural Remote Health 2020;20:6045.

54. Siow WT, Liew MF, Shrestha BR, et al. Managing COVID-19 in resource-limited settings: critical care considerations. Crit Care 2020;24:167.

55. Heaven WD. Israel is using AI to flag high-risk covid-19 patients. MIT Technology Review. Accessed April 24, 2020. Available online: https://www.technologyreview. com/2020/04/24/1000543/israel-ai-prediction-medicaltesting-data-high-risk-covid-19-patients/

56. Yavoruk O. Teaching Physics Using Equidistant AR/ VR-Projections. In: Proceedings from the 2019 The 3rd International Conference on Digital Technology in Education. Yamanashi: 2019; pp 48-51.

57. Zhang N, Mi X, Feng X, et al. Understanding and Mitigating the Security Risks of Voice-Controlled ThirdParty Skills on Amazon Alexa and Google Home. arXiv: 1805.01525 [arXiv preprint]. Available online: https://arxiv. org/abs/1805.01525v2

58. Park CL, Russell BS, Fendrich M, et al. Americans' COVID-19 Stress, Coping, and Adherence to CDC Guidelines. J Gen Intern Med 2020;35:2296-303.

59. TOFEL KC. How the COVID-19 pandemic is spurring IoT growth while the world's business slows. Stacey on IoT. Accessed MAY 6, 2020. Available online: https:// staceyoniot.com/how-the-covid-19-pandemic-is-spurringiot-growth-while-the-worlds-business-slows/
60. Singh RP, Javaid M, Haleem A, et al. Internet of things (IoT) applications to fight against COVID-19 pandemic. Diabetes Metab Syndr 2020;14:521-4.

61. Vaishya R, Javaid M, Khan IH, et al. Artificial Intelligence (AI) applications for COVID-19 pandemic. Diabetes Metab Syndr 2020;14:337-9.

62. Perez S. COVID-19 quarantine boosts smart speaker usage among U.S. adults, particularly younger users. Techcrunch. Accessed May 1, 2020. Available online: https://techcrunch.com/2020/04/30/covid-19-quarantineboosts-smart-speaker-usage-among-u-s-adultsparticularly-younger-users/

63. Khan MA, Shahid MHB, Mansoor H, et al. IoT based Grocery Management System: Smart Refrigerator and Smart Cabinet. In: Proceedings from 2019 International Conference on Systems of Collaboration Big Data, Internet of Things \& Security (SysCoBIoTS), 2019, Casablanca, Morocco, p. 1-5.

64. Malay DS. COVID-19, Pandemic, and Social Distancing. J Foot Ankle Surg 2020;59:447-8.

65. Bai L, Yang D, Wang X, et al. Chinese experts' consensus on the Internet of Things-aided diagnosis and treatment of coronavirus disease 2019 (COVID-19). Clin eHealth 2020;3:7-15.

66. Mohammed MN, Syamsudin H, Al-Zubaidi S, et al. Novel COVID-19 detection and diagnosis system using IOT based smart helmet. Int J Psychosoc Rehabil 2020; 24:2296-303.

67. Megvii Technology Ltd. Megvii's AI-enabled temperature screening solution deployed at nearly 200 supermarkets in Beijing. Megvii. Accessed April 09, 2020. Available online: https://megvii.com/en/news/ID?news_id=130

68. Zhang R, Chen W, Xu M, et al. Analysis and Design of Voice Assisted Learning System Based on Baidu AI. In: 2019 IEEE International Conference on Computer Science and Educational Informatization (CSEI). Kunming, China: IEEE; 2019, 334-6.

69. Orlando JI, Fu H, Barbosa Breda J, et al. REFUGE Challenge: A unified framework for evaluating automated methods for glaucoma assessment from fundus photographs. Med Image Anal 2020;59:101570.

70. Storck CR, Duarte-Figueiredo F. A 5G V2X Ecosystem Providing Internet of Vehicles. Sensors (Basel) 2019;19:550.

71. Chávez-Santiago R, Szydełko M, Kliks A, et al. 5G: The Convergence of Wireless Communications. Wirel Pers Commun 2015;83:1617-42.

72. TOFEL KC. Do you need a smart smoke detector or can 
you use existing smart devices to listen for alarms? Stacey on IoT. Accessed June 17, 2020. Available online: https:// staceyoniot.com/smart-smoke-detector-vs-smart-deviceslisten-for-alarm/

73. Lo HA, Huang JJ, Chen CC, et al. CommunityBased Epidemic Prevention in Taiwan: Combating the Coronavirus Disease-2019 Crisis. Disaster Med Public Health Prep 2020;14:e15-6.

74. SmileDirectClub, Inc. Smile Direct Club to Produce Face Shields for Medical Personnel Amidst COVID-19 Pandemic. SmileDirectClub. Accessed March 26, 2020. Available online: https://investors.smiledirectclub.com/ news-releases/news-release-details/smile-direct-clubproduce-face-shields-medical-personnel-amidst/

75. Li W, Mao W, Zhang M, et al. Design of Persuasive APP Based on IOS System--Taking Intelligent Mask as an Example. In: IOP Conference Series: Materials Science and Engineering. Luoyang, China: IOP Publishing, 2019;573:012030.

76. Briggs H. Coronavirus: Satellite traffic images may suggest virus hit Wuhan earlier. BBC news. Accessed June 09, 2020. Available online: https://www.bbc.com/news/worldus-canada-52975934

77. Lin L, Hou Z. Combat COVID-19 with artificial intelligence and big data. J Travel Med 2020;27:taaa080.

78. Alessa A, Faezipour M. A review of influenza detection and prediction through social networking sites. Theor Biol Med Model 2018;15:2.

79. Qiu HJ, Yuan LX, Huang XK, et al. Using the big data of internet to understand the characteristics of coronavirus disease 2019: a big data study. Zhonghua Er Bi Yan Hou Tou Jing Wai Ke Za Zhi 2020;5 5:569-75.

80. Du RH, Liang LR, Yang CQ, et al. Predictors of mortality for patients with COVID-19 pneumonia caused by SARS-CoV-2: a prospective cohort study. Eur Respir J 2020;55:2000524.

81. Gharavi E, Nazemi N, Dadgostari F. Early outbreak detection for proactive crisis management using twitter data: Covid-19 a case study in the US. arXiv preprint. arXiv:2005.00475.

82. Niiler E. An AI Epidemiologist Sent the First Warnings of the Wuhan Virus. WIRED. Accessed January 25, 2020. Available online: https://www.wired.com/story/aiepidemiologist-wuhan-public-health-warnings/

83. Rockefeller Neuroscience Institute. WVU Rockefeller Neuroscience Institute and Oura Health unveil study to predict the outbreak of COVID-19 in healthcare professionals. WVUTODAY. Accessed April 08,
2020. Available online: https://wvutoday.wvu.edu/ stories/2020/04/08/wvu-rockefeller-neuroscienceinstitute-and-oura-health-unveil-study-to-predict-theoutbreak-of-covid-19-in-healthcare-professionals

84. Snider M. Apple Watch, Fitbit as first line of defense? Tests expand on whether wearables could predict coronavirus. USA TODAY. Accessed June 5, 2020. Available online: https://www.usatoday.com/story/ tech/2020/05/27/coronavirus-tracking-apple-watch-fitbitstudies-aim-detect-covid-19/5270949002/

85. UCSF Health Hospital Epidemiology and Infection Prevention. COVID-19: Algorithms and Clinical Guidance. University of California San Francisco. Accessed March, 2020. Available online: https://infectioncontrol. ucsfmedicalcenter.org/coronavirus/algorithms

86. Panwar H, Gupta PK, Siddiqui MK, et al. Application of deep learning for fast detection of COVID-19 in X-Rays using nCOVnet. Chaos Solitons Fractals 2020;138:109944.

87. Yu Q, Wang Y, Huang S, et al. Multicenter cohort study demonstrates more consolidation in upper lungs on initial CT increases the risk of adverse clinical outcome in COVID-19 patients. Theranostics 2020;10:5641-8.

88. Oh Y, Park S, Ye JC. Deep Learning COVID-19 Features on CXR Using Limited Training Data Sets. IEEE Trans Med Imaging 2020;39:2688-700.

89. El Asnaoui K, Chawki Y. Using X-ray images and deep learning for automated detection of coronavirus disease. J Biomol Struct Dyn 2020. [Epub ahead of print].

90. Khan AI, Shah JL, Bhat MM. CoroNet: A deep neural network for detection and diagnosis of COVID-19 from chest $\mathrm{x}$-ray images. Comput Methods Programs Biomed 2020;196:105581.

91. Dubovitskaya A, Xu Z, Ryu S, et al. Secure and Trustable Electronic Medical Records Sharing using Blockchain. AMIA Annu Symp Proc 2018;2017:650-9.

92. Liang $\mathrm{W}$, Tang $\mathrm{M}$, Long $\mathrm{J}$, et al. A secure fabric blockchain-based data transmission technique for industrial Internet-of-Things. IEEE Trans Industr Inform 2019;15:3582-92.

93. Kishigami J, Fujimura J, Watanabe S, et al. The blockchain-based digital content distribution system. In: 2015 IEEE Fifth International Conference on Big Data and Cloud Computing. Dalian, China: IEEE, 2015, p187-90.

94. Wandner SA, O'Leary CJ. An Unemployment Insurance COVID-19 Crisis Response. Employ Res Newsl 2020;27:2.

95. Xiao L, Cheng Y, Deng H, et al. Insurance Block: An 
Insurance Data Security Transaction Authentication Scheme Suitable for Blockchain Environment. In: International Conference on Smart Blockchain. Birmingham, UK: Springer, Cham, 2019, p120-9.

96. Yasaka TM, Lehrich BM, Sahyouni R. Peer-to-Peer Contact Tracing: Development of a Privacy-Preserving Smartphone App. JMIR Mhealth Uhealth 2020;8:e18936.

97. Ekong I, Chukwu E, Chukwu M. COVID-19 Mobile Positioning Data Contact Tracing and Patient Privacy Regulations: Exploratory Search of Global Response Strategies and the Use of Digital Tools in Nigeria. JMIR Mhealth Uhealth 2020;8:e19139.

98. Terra news. Terra Drone business partner Antwork helps fight coronavirus in China with medical delivery drones. TerraDrone. Accessed February 07, 2020. Available online: https://www.terra-drone.net/global/2020/02/07/terradrones-business-partner-antwork-helps-fighting-coronavirus-with-drones/

99. Preethika T, Vaishnavi P, Agnishwar J, et al. Artificial Intelligence and Drones to Combat COVID-19. Preprints, 2020, 2020060027.

100. Rosser JC Jr, Vignesh V, Terwilliger BA, et al. Surgical and Medical Applications of Drones: A Comprehensive Review. JSLS 2018;22:e2018.00018.

101. Chen B, Marvin S, While A. Containing COVID-19 in China: AI and the robotic restructuring of future cities. Dialogues Hum Geogr 2020;10:238-41.

102. Khan ZH, Siddique A, Lee CW. Robotics Utilization for Healthcare Digitization in Global COVID-19 Management. Int J Environ Res Public Health 2020;17:3819.

103.Shi YL. China's Shenyang develops robots, intelligence industry. XINHUANET. Accessed August 13, 2018. Available online: http://www.xinhuanet.com/ english/2018-08/13/c_137387497.htm

104. Meisenzahl M. How Asia, the US, and Europe are using robots to replace and help humans fight coronavirus by delivering groceries, sanitizing hospitals, and monitoring patients. Business Insider. Accessed April 03, 2020. Available online: https://www.businessinsider.com/robotsfighting-coronavirus-in-china-us-and-europe-2020-3

105. Bieller S. Robots on the front line of keeping people safe from the coronavirus. IFR, International Federation of Robotics. Accessed April 01, 2020. Available online: https://ifr.org/post/robots-on-the-front-line-of-keepingpeople-safe-from-the-coronavirus

106.Xinhua. Disinfection robots put to work fighting COVID-19. CHINADAILY. Accessed February 12,
2020. Available online: https://www.chinadaily.com.cn/ a/202002/12/WS5e438906a310128217276fa7_1.html

107. Wu CS, Liao H, Wang YB, et al. Design of intelligent utility-interactive inverter with AI detection. In: 2008 Third International Conference on Electric Utility Deregulation and Restructuring and Power Technologies. Nanjing, China, CA: IEEE, 2008;2012-17.

108. Kumar V. AI-Powered Real-Time Fever Detection Camera Assists in COVID-19 Screening. Analytics Insight. Accessed May 06, 2020. Available online: https://www. analyticsinsight.net/ai-powered-real-time-fever-detectioncamera-assists-covid-19-screening/

109. Blue Ocean Robotics ApS. Blue Ocean Robotics builds UV-D disinfection robot. Robotics Business Review. Available online: https://www.roboticsbusinessreview. com/rbr50-company/blue-ocean-robotics-builds-uv-ddisinfection-robot/

110. Fingas J. Starship's delivery robots now serve Purdue University. Engadget. Accessed September 09, 2019. Available online: https://www.engadget.com/2019-09-09starship-delivery-robots-at-purdue-university.html

111.Jumper J, Tunyasuvunakool K, Kohli P, et al. Computational predictions of protein structures associated with COVID-19. DeepMind. Accessed April 08, 2020. Available online: https:/www.deepmind.com/research/ open-source/computational-predictions-of-proteinstructures-associated-with-COVID-19

112. Potential Treatment For COVID-19 Identified By Benevolent AI Enters Randomised Clinical Trial. Benevolent. Accessed April 10, 2020. Available online: https:/www.benevolent.com/news/potential-treatmentfor-covid-19-identified-by-benevolentai-using-artificialintelligence-enters-randomised-clinical-trial

113. Kharpal A. China's giants from Alibaba to Tencent ramp up health tech efforts to battle coronavirus. CNBC.

Accessed March 03, 2020. Available online: https://www. cnbc.com/2020/03/04/coronavirus-china-alibaba-tencentbaidu-boost-health-tech-efforts.html

114.Huang I, Chang W. Taiwan's Leading-Edge Technologies Help Tackle COVID-19. SEMI. Accessed May 19, 2020. Available online: https://blog.semi.org/technology-trends/ taiwans-leading-edge-technologies-help-tackle-covid-19

doi: $10.21037 / \mathrm{ht}-20-27$

Cite this article as: Tsai $\mathrm{W}$, Chang WH. Reviewing the trend of health artificial intelligence technology in COVID-19 pandemic prevention. Health Technol 2021;5:5. 